\title{
Small-angle scattering from GP zones in Al-Cu alloy
}

\author{
K T KASHYAP* and PRAVEENNATH G KOPPAD \\ Department of Mechanical Engineering, PES Institute of Technology, Bangalore 560 050, India
}

MS received 30 July 2009; revised 11 February 2011

\begin{abstract}
It is well known that Guinier Preston (GP) zones form in Al-Cu alloys upon solutionizing and artificial aging, which are extensively used in commercial practice. It is well established that GP zones are discshaped precipitates, i.e. disks of clusters of copper atoms in the FCC aluminium matrix. These disks have coherency strain fields in aluminium that give the alloy its high yield strength. The formation of GP zones in the supersaturated aluminium matrix is thought to be heterogeneous nucleation and growth. Some authors have believed that the formation of GP zones is by spinodal decomposition of the supersaturated Al-Cu solid solution. The main objective of the present work is to test whether spinodal decomposition is responsible for the formation of GP zones in Al-Cu alloy. The experimental alloy AA2219 was selected for its high copper content $(\mathrm{Al}-6 \% \mathrm{Cu}-0 \cdot 2 \% \mathrm{Zr})$. After solutionizing and artificial aging, the aging curve was plotted and smallangle scattering experiments were carried on the powdered samples as a function of time during artificial aging. Small-angle scattering data were analysed, and evidence has been obtained for the occurrence of spinodal decomposition as the mechanism responsible in the early stages of formation of GP zones.
\end{abstract}

Keywords. GP zones; nucleation and growth; spinodal decomposition; Al-Cu alloy.

\section{Introduction}

It is well known that $\mathrm{Al}-\mathrm{Cu}$ alloys are precipitation hardenable (Martin 1968; Polmear 1989). It is well known that the supersaturated solid solution in $\mathrm{Al}-\mathrm{Cu}$ alloy precipitates Guinier Preston zones (GP zones) (Martin 1968; Polmear 1989). The GP zones form on (200) planes of the $\mathrm{Al} f c c$ crystal from the work of Gerold (1954). The GP zones are discs on (200) planes perpendicular to the (100) directions in $f c c$ aluminium which are elastically soft directions. Precipitation in $\mathrm{Al}-\mathrm{Cu}$ alloy has been studied by transmission electron microscopy (TEM) by Nicholson and Nutting (1958); Nicholson et al (1958-1959) and Weatherly and Nicholson (1968). They all have identified GP zones, metastable precipitates $\theta^{\prime \prime}$, $\theta$ and equilibrium precipitate $\theta\left(\mathrm{CuAl}_{2}\right)$ as the precipitation sequence in $\mathrm{Al}-\mathrm{Cu}$ alloys.

In their work Karlik and Jouffrey (1997) confirmed the presence of monolayers of GP zones in the form of discs of 4-10 $\mathrm{nm}$ in diameter by means of high-resolution electron microscopy and that there are layers of $\mathrm{Cu}$ in (200) planes in the aluminium matrix. According to their simulations of GP 1 zones column, there is a variation of copper content from GP 1 column to the depleted matrix. They have not commented on the formation of GP zones (Karlik and Jouffrey 1997). On the other hand, using tomographic atom field ion microscopy, Karlik et al

\footnotetext{
*Author for correspondence (ktkashyap@yahoo.com)
}

(2004) showed the different $\mathrm{Cu}$ concentrations ranging from 40 to $100 \% \mathrm{Cu}$ coexist in the GP zones, and they also plotted the concentration profile of $\mathrm{Cu}$ in the GP zone and close to the GP zone. They have shown that Al$\mathrm{Cu}$ system shows the variety of metastable states following the sequence $\mathrm{SSS} \rightarrow \mathrm{GP} 1$ zones $\rightarrow$ GP 2 zones $\left(\theta^{\prime}\right) \rightarrow \theta^{\prime} \rightarrow \theta\left(\mathrm{CuAl}_{2}\right)$. Since the size of the $\mathrm{Cu}$ atoms is smaller than $\mathrm{Al}$ atoms, the crystallographic planes (200) collapse to the disk of GP 1 zone, thus creating a coherency strain field. However, the authors have not commented on the formation mechanism of the GP 1 zones (Karlik et al 2004). A thermodynamic analysis was done by Jing et al (2008) on GP zones where they have used quasichemical model of solution thermodynamics. The $\mathrm{Al}-\mathrm{Cu}$ binary phase diagram was calculated where the GP zone solvus curve was found to be a miscibility gap. However, they have not given any evidence for spinodal decomposition of formation of GP zones in Al-Cu alloy (Jing et al 2008). However, Rioja and Laughlin (1977) interpreted the observation of diffuse satellites in selected area electron diffraction patterns, as evidence for spinodal decomposition.

The major reviews of precipitation by Kelly and Nicholson (1968) and Russel and Aaronson (1978) state that the formation mechanism for GP zones is heterogeneous nucleation and growth. Some authors, for example, Smallman (2009) suggest that the formation of GP zones could be by spinodal decomposition. The subject of spinodal decomposition has been proposed elegantly by Cahn in his classic paper (Cahn 1968). Rundman and Hilliard (1967) verified Cahn's theory of spinodal 
decomposition (Rioja and Laughlin 1977) in the Al-Zn system by small-angle scattering of X-rays.

As far as GP zones are concerned, the GP zone solvus on the binary $\mathrm{Al}-\mathrm{Cu}$ phase diagram has been suggested by Smallman (2009) to be part of a miscibility gap. With this background, the objective of the present paper is to test whether GP zones form by spinodal decomposition or nucleation and growth in the early stages of their formation in the $\mathrm{Al}-\mathrm{Cu}$ alloy.

\section{Experimental}

Commercial aluminium alloy AA2219 with a chemical composition of $\mathrm{Al}-6 \mathrm{wt} \% \mathrm{Cu}-0.2 \mathrm{wt} \% \mathrm{Zr}$ was selected because of the high copper content. AA2219 was DC-cast and hot-extruded at $450^{\circ} \mathrm{C}$ to a plate. Samples were cut from this plate and solution annealed at $540^{\circ} \mathrm{C}$ for $1 \mathrm{~h}$, followed by water quenching and artificially aged at $150^{\circ} \mathrm{C}$ for $2,4,8,40,100,150$ and $200 \mathrm{~min}$. Hardness testing was carried on a Vicker's hardness tester at $5 \mathrm{~kg}$ load. Powders were filed from the samples and small-angle X-ray scattering was performed on a BRUKER SAXS (Nanostar) with a rotating anode with $45 \mathrm{kV}$ and $100 \mathrm{~mA}$ power. The distance of the detector was $26 \mathrm{~cm}$ from the sample chamber. The small-angle X-ray scattering was carried out as a function of artificial aging time. The plots of intensity vs $q(2 \pi / \lambda)$ and intensity vs $q^{2}$ and $\ln I$ vs $\ln q$ were generated for analysis of the spectra. The smallangle scattering data were analysed using the Guinier approximation.

\section{Results and discussion}

Figure 1 shows the aging curve (Vicker's hardness vs aging time) for AA2219 solutionized at $540^{\circ} \mathrm{C}$, water quenched and artificially aged at $150^{\circ} \mathrm{C}$ for $2,4,8,40$, 100,150 and $200 \mathrm{~min}$. The curve shows the peak hardness at $50 \mathrm{~min}$ at $150^{\circ} \mathrm{C}$. This means that GP 1 zones are forming and growing at 2, 4, 8 and $40 \mathrm{~min}$, which were studied by small-angle scattering spectra. Figures 2-4 show the small-angle spectra of the samples aged at $150^{\circ} \mathrm{C}$ for 2,4 and $8 \mathrm{~min}$, respectively. At about $q=0.04$ $(q=2 \pi / \lambda)$, there is a peak in the spectrum that goes on increasing with intensity, as seen in the spectra shown in the figures. This is a characteristic peak of GP 1 zones which occurs at the value of $q$, i.e. 0.04. Figures 5-7 show intensity vs $q^{2}$ for the same three samples. It is found that the Guinier approximation to the small-angle spectra can be applied. From the Guinier approximation of the small-angle scattering data (Fultz and Howe 2005), the following equation holds good:

$$
I(\Delta q)=N^{2}|F(0)|^{2} \exp \left[-\left(\Delta q \times r_{\mathrm{g}}\right)^{2} / 3\right],
$$

$I(\Delta q)$, is the intensity scattered at small angles, $N$ is the number of unit cells, $F(0)$ is the structure factor $r_{\mathrm{g}}$, is the radius of gyration of the particles and $q$ is the $2 \pi / \lambda$.
From figures 5-7 and for other samples, the radius of gyration was obtained by the Guinier approximation (Fultz and Howe 2005). The radius of gyration was obtained as the slope of $\ln I$ vs $q^{2}$ plots. Figure 8 shows the plot of radius of gyration vs time of aging ( $\left.r_{\mathrm{g}} \mathrm{vs} t\right)$. The

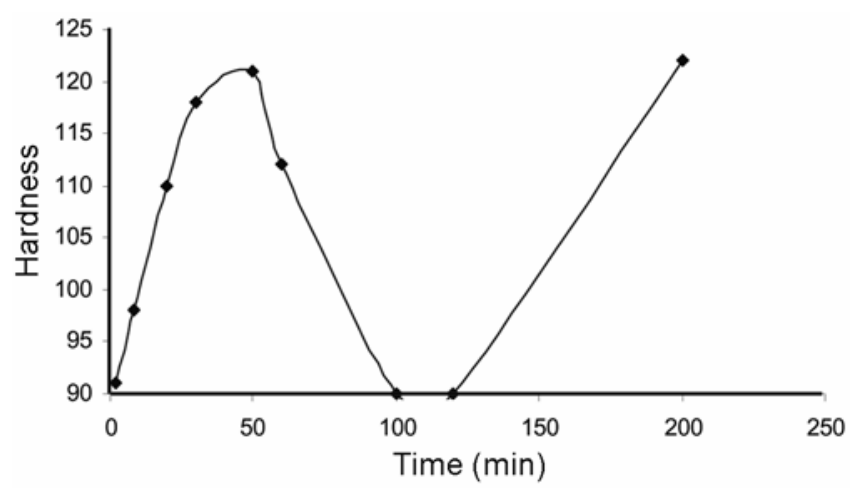

Figure 1. Aging curve (Vicker's hardness vs aging time) for AA2219 solutionized at $540^{\circ} \mathrm{C}$.

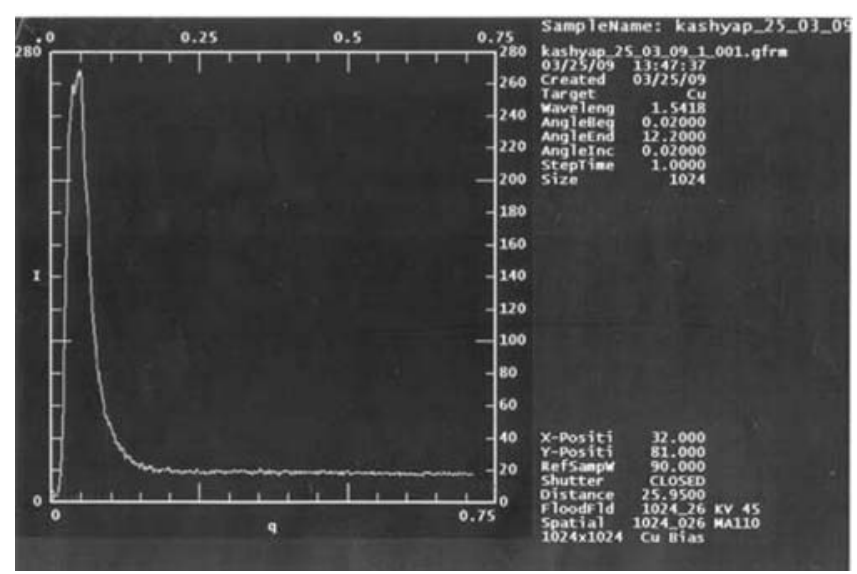

Figure 2. Small-angle spectra of samples aged at $150^{\circ} \mathrm{C}$ for 2 min.

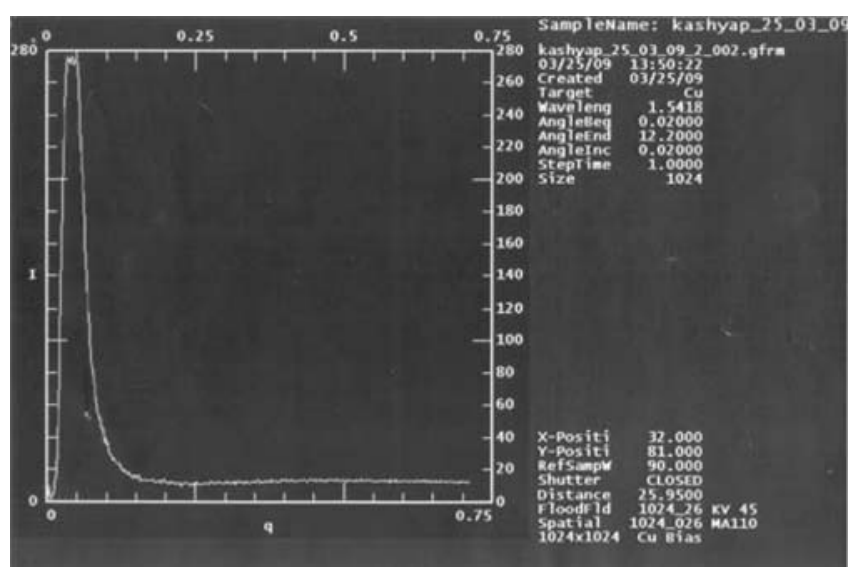

Figure 3. Small-angle spectra of samples aged at $150^{\circ} \mathrm{C}$ for 4 min. 
radius of gyration is seen to increase from $33 \AA$ to $44 \AA$, indicating growth of GP 1 zones. From Cahn's theory of spinodal decomposition (Cahn 1968) as verified by

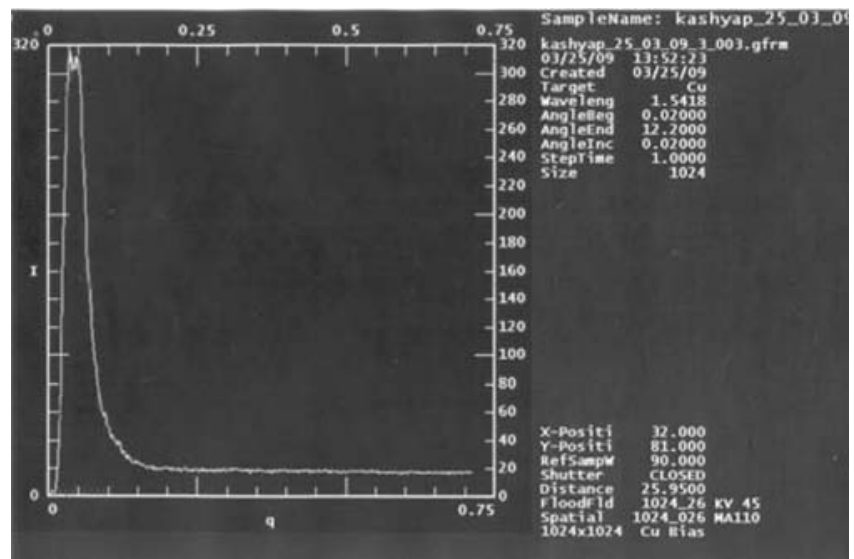

Figure 4. Small-angle spectra of the samples aged at $150^{\circ} \mathrm{C}$ for $8 \mathrm{~min}$.

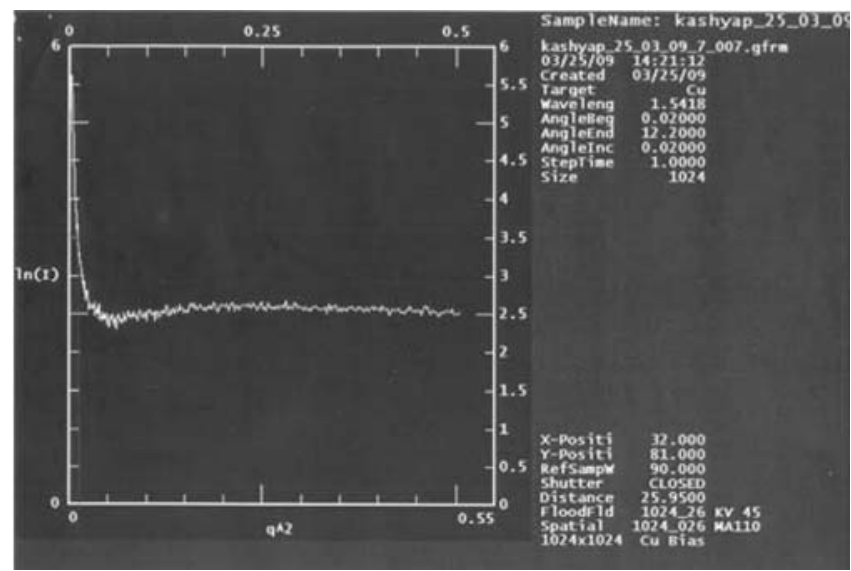

Figure 5. Intensity vs $q^{2}$ for samples aged at $150^{\circ} \mathrm{C}$ for 2 min.

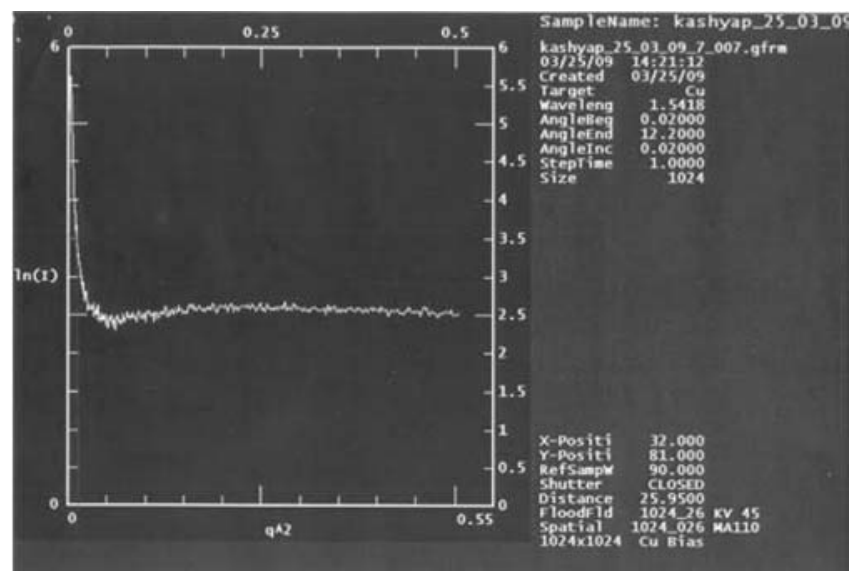

Figure 6. Intensity vs $q^{2}$ for samples aged at $150^{\circ} \mathrm{C}$ for 4 min.
Rundman and Hilliard (1967) in Al-Zn system, the following equation holds good:

$$
I(\beta, t)=I(\beta, 0) \exp [2 R(\beta) t],
$$

$I(\beta, t)$ is the scattered intensity at time $t, I(\beta, 0)$ is the scattered intensity at time $t=0, R(\beta)$ is the amplification factor and $t$ is the time.

$\ln I(\beta, t)=\ln I(\beta, 0)+R(\beta) t$ is a straight line with slope of $R(\beta)$. The amplification factor in the original analysis dictates the extent to which sinusoidal fluctuations, i.e. concentration profiles grow with a particular wavelength which in this case is the reciprocal of $q$.

Figure 9 shows the plot of $\ln I$ vs $t$ (time) at aging at $150^{\circ} \mathrm{C}$. At small times $(2,4$ and $8 \mathrm{~min})$, a straight line can be plotted with a $R(\beta)$ value of $0 \cdot 1038$. At larger times, slope $R(\beta)$ is 0.003 .

This straight line relationship between $\ln I$ vs time with a positive slope of $R(\beta)$ is direct evidence for spinodal decomposition in $\mathrm{Al}-6 \mathrm{wt} \% \mathrm{Cu}-0 \cdot 2 \mathrm{wt} \% \mathrm{Zr}$ (AA2219) at $150^{\circ} \mathrm{C}$ aging. This means that the fluctuations in the matrix grow with time. This concurs with the Rundman and Hilliard's experiment (1967) on Al-Zn to test the validity of Cahn's theory of spinodal decomposition (Cahn 1968). This evidence concurs with the Rioja and Laughlin (1977) from satellite spots of electron diffraction pattern from GP 1 zones in $\mathrm{Al}-\mathrm{Cu}$ alloy. This analysis also

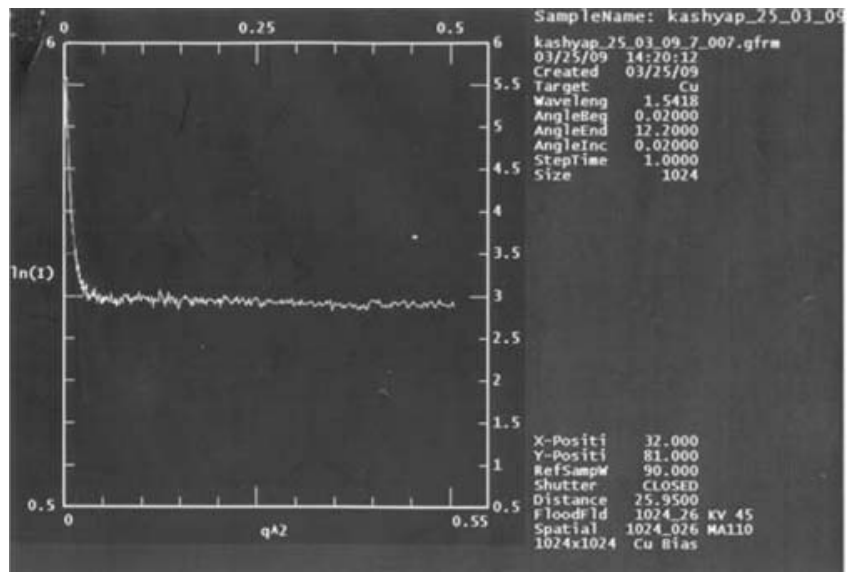

Figure 7. Intensity vs $q^{2}$ for samples aged at $150^{\circ} \mathrm{C}$ for 8 min.

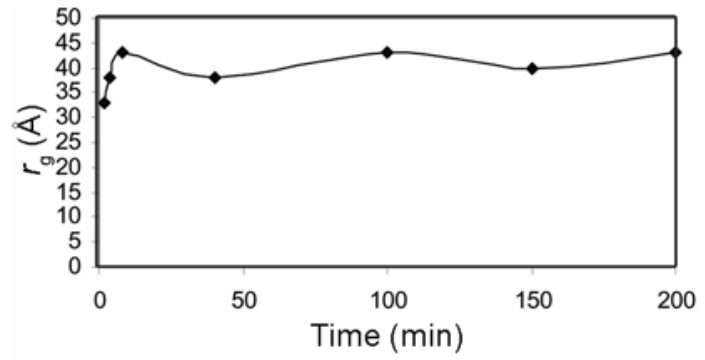

Figure 8. Plot of radius of gyration $\left(r_{\mathrm{g}}\right)$ vs time. 


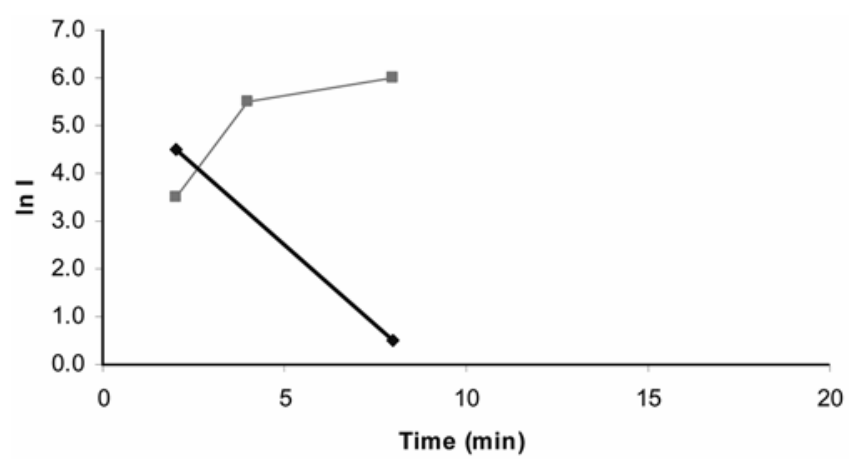

Figure 9. Plot of $\ln I$ vs $t$ (time) at aging at $150^{\circ} \mathrm{C}$.

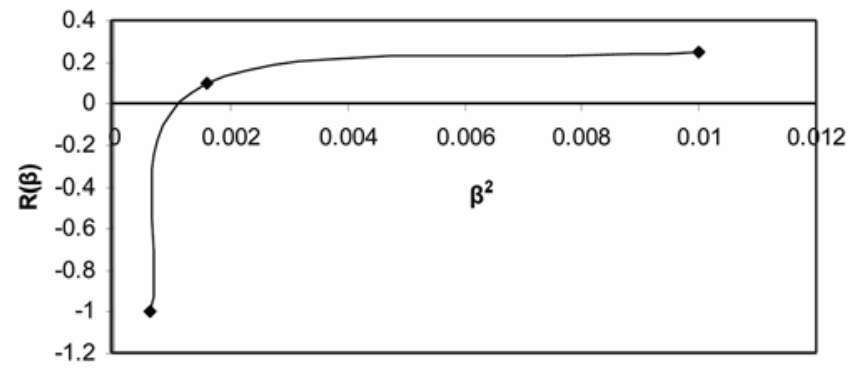

Figure 10. Plot $R(\beta)$ vs $\beta^{2}$.

concurs with Jing et al (2008) on the thermodynamic analysis of GP 1 zones wherein they predicted from solution thermodynamics that there exists a miscibility gap for GP 1 zone solvus in Al-Cu alloy. As far as high volume of literature on GP 1 zones $\mathrm{Al}-\mathrm{Cu}$-based alloys is concerned, for example, Karlik and Jouffrey (1997), Karlik et al (2004) and Gerold (1954), there has been no evidence for the formation of GP 1 zones by spinodal decomposition. It is noteworthy to understand that Karlik et al (2004) although they measured the concentration profile of $\mathrm{Cu}$ atom $\% \mathrm{Cu}$ in the GP 1 zone and the depleted matrix close to GP 1 zone, they have found the intensity of $\mathrm{Cu}$ atoms to be 20 atom $\% \mathrm{Cu}$, which can be cogently argued that there is uphill diffusion of copper atoms, which is a characteristic feature of spinodal decomposition. The work of Karlik and Jouffrey (1997) gives the copper content of GP 1 zone and also the morphology of GP 1 zone by HRTEM. The conventional approach, for example, Russel and Aaranson (1978) is to assume that the formation of GP 1 zone is by nucleation and growth, especially heterogeneous nucleation. The present authors propose, on the basis of small-angle scattering data, that the concentration profile of the GP 1 zone can be a direct consequence of uphill diffusion, i.e. spinodal decomposition.

Figure 10 shows the plot of $R(\beta)$, the amplification factor, as a function of $\beta^{2}$, i.e. wave number squared. It is seen that the amplification factor is negative for $\beta$ values that are less than $1.5 \times 10^{-3} \mathrm{~nm}^{-1}$ and it is positive for values of greater than this. This means the wavelengths greater than $1.5 \times 10^{-3} \mathrm{~nm}^{-1}$ are growing into GP 1 zones.
Figure 10 is a classic figure for spinodal decomposition. This shows that the sinusoidal variations below the critical wavelength are decaying and above the critical wavelength are growing into GP 1 zones. The critical wavelength happens to be $1.5 \times 10^{-3} \mathrm{~nm}^{-1}$. This figure supports the model for spinodal decomposition of GP 1 zones in $\mathrm{Al}-\mathrm{Cu}$ system which concurs with the work of Jing et al (2008) and Rioja and Laughlin (1977).

From the plots $\ln I$ vs $\ln q$, the slopes were found to be non-integral values of $2 \cdot 4$, indicative of diffuse interface between the GP zones and aluminium matrix (Fultz and Howe 2005). This result is further indicative of spinodal decomposition of GP 1 zones where the interface between GP 1 and aluminium matrix is found to be diffuse as against a sharp interface for nucleation and growth transformation.

\section{Conclusion}

The GP 1 zones in $\mathrm{Al}-\mathrm{Cu}$ system, i.e. $\mathrm{Al}-6 \% \mathrm{Cu}-0 \cdot 2 \% \mathrm{Zr}$, form by spinodal decomposition in the early stages, as seen from direct evidence obtained from small-angle scattering spectra.

\section{Acknowledgements}

The authors are grateful to acknowledge $\mathrm{Dr}$ T N Gururow, SSCU, IISc, Bangalore, for providing the smallangle X-ray scattering facility, and to Srinivas for carrying out the experiments. The authors also acknowledge Prof D Jawahar, CEO, PES Group of Institutions, and Dr K N B Murthy, Principal and Director, PESIT, Bangalore.

\section{References}

Cahn J W 1968 The 1967 institute of metals lecture 242166

Fultz B and Howe J M 2005 Transmission electron microscopy and diffractometry of materials (Springer-Verlag)

Gerold V 1954 Zeitschrift fur Metallkunde 45599

Jing Y, Li C, Du Z, Wang F and Song Y 2008 Calphad 32164

Karlik M and Jouffrey B 1997 Acta Mater. 453251

Karlik M, Bigot A, Jouffrey B, Auger P and Belliot S 2004 Ultramicroscopy 98219

Kelly A and Nicholson R B 1968 Precipitation hardening, in Progress in materials science (New York: Macmillan) Vol. 10, p. 149

Martin J W 1968 Precipitation hardening (Oxford: Pergamon Press)

Nicholson R B and Nutting J J 1958 Philos. Mag. 3531

Nicholson R B, Thomas G C and Nutting J J 1958-1959 Inst. Met. 87431

Polmear I 1989 Light alloys (Edward Arnold) 2nd edn

Rioja R J and Laughlin D E 1977 Metall. Trans. A8 1257

Rundman K B and Hilliard J E 1967 Acta Metall. 151025

Russel K C and Aaranson H I (eds) 1978 Precipitation processes solids (Warrendale, PA: The Metallurgical Society of AIME)

Smallman R E 2009 Physical metallurgy and advanced materials (Butterworth, Heineman: Elsevier) 7th edn

Weatherly G C and Nicholson R B 1968 Philos. Mag. 17813 